\title{
Presentation of
}

\section{Nina Robbins}

Adjunct Professor Nina Robbins is currently working as a university lecturer in Museum Studies at the University of Helsinki. She is a long-term museum professional and holds prior MA degrees in art conservation and art history. Over the years she has worked as a collection manager, conservator, curator and museum

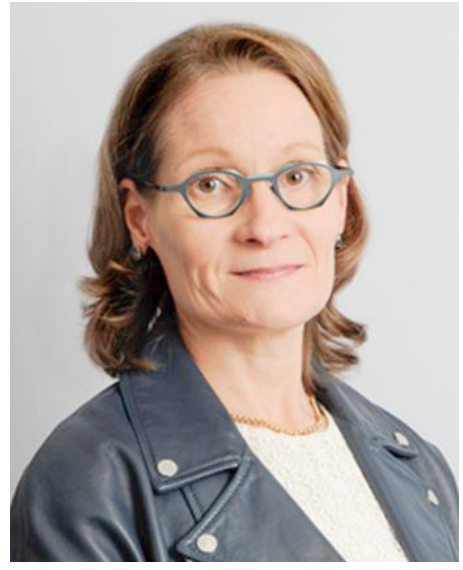

Nina Robbins. Photo: University of Jyväskylä.

director in the museum field. In her teaching she is placing great importance in passing on to her university students not only theoretical knowledge, but also its corresponding practical knowledge. She feels that the field of museology offers an enduring bridge between the various fields of heritage management. Beneficially integrating the forces from these different fields will become ever more important in a world where financial resources are increasingly scrutinized. She also believes it is important to work towards raising the status of humanistic studies. In this work the concepts of life-long learning and creating methods where the distance between theory and practice can be bridged are important.

In the museum field it is important to find practical applications of theoretical knowledge, increasing the impact potential of museums. Nina's research interests have involved the concept of Museological Value Discussion and finding ways that this discussion could become as a tool that museum professionals could use in everyday museum practices. Her Ph.D. thesis and published articles have mapped this discussion from various perspectives. In terms of practical museum work, themes such as developing collection management towards collection development and analyzing the long-term significance of collections are especially important. On a theoretical level, gathering information as to how accumulated humanistic values can be an indicator of long-term impact or finding ways that humanistic values can become part of the latest economic theories related to a more sustainable future are interesting to her. Research in these areas will eventually result in more substantial museum professionalism.

Adjunct Professor Nina Robbins nina.robbins@helsinki.fi

University of Helsinki 